\title{
Association between hypomagnesemia and severity of primary hyperparathyroidism: a retrospective study
}

\author{
Ding $\mathrm{Na}^{1 \dagger}{ }^{1}$, Guo Tao ${ }^{2 \dagger}$, Liu Shu-Ying ${ }^{1}$, Wang Qin-Yi ${ }^{1}$, Qu Xiao-Li ${ }^{1}$, Li Yong-Fang ${ }^{1}$, Ou Yang-Na ${ }^{3}$,
} Sheng Zhi-Feng ${ }^{1 *}$ and Yang Yan-Yi ${ }^{4^{*}}$

\begin{abstract}
Background: The occurrence of hypomagnesemia in patients with primary hyperparathyroidism (PHPT) has been noted previously; however, the association of hypomagnesemia and severity of primary hyperparathyroidism remains unknown. The present study aimed to evaluate the association of hypomagnesemia with biochemical and clinical manifestations in patients with PHPT.

Methods: This was a retrospective study conducted at a tertiary hospital. We obtained data from 307 patients with PHPT from January 2010 through August 2020. Data on demographics, history, laboratory findings, bone densitometry findings, and clinical presentation and complications were collected and were compared in normal magnesium group vs hypomagnesemia group.

Results: Among the 307 patients with PHPT included in our study, 77 patients (33/102 [32.4\%] males and 44/205 [21.5\%] females) had hypomagnesemia. Mean hemoglobin levels in the hypomagnesemia group were significantly lower than those in the normal magnesium group in both males and females. In contrast, patients with hypomagnesemia had a higher mean serum calcium and parathyroid hormone than individuals with normal magnesium. The typical symptoms of PHPT, such as nephrolithiasis, bone pain/fractures, polyuria, or polydipsia, were more common in the hypomagnesemia group. In addition, patients with hypomagnesemia had a higher prevalence of osteoporosis, anemia, and hypercalcemic crisis. Even after adjusting for potential confounders, including age, sex, body mass index, estimated glomerular filtration rate, and parathyroid hormone levels, these associations remained essentially unchanged.

Conclusion: Biochemical and clinical evidence indicates that patients with PHPT with hypomagnesemia have more severe hyperparathyroidism than those without hypomagnesemia. In addition, PHPT patients with hypomagnesemia had a higher prevalence of osteoporosis, anemia, and hypercalcemic crisis.
\end{abstract}

Keywords: Primary hyperparathyroidism, Hypomagnesemia, Severity, Biochemical, Clinical

\footnotetext{
* Correspondence: shengzhifeng@csu.edu.cn; yangyanyi162@csu.edu.cn

${ }^{\dagger}$ Ding $\mathrm{Na}$ and Guo Tao contributed equally to this work.

'National Clinical Research Center for Metabolic Diseases, Hunan Provincial

Key Laboratory of Metabolic Bone Diseases, Department of Metabolism and

Endocrinology and Health Management Center, The Second Xiangya

Hospital of Central South University, Changsha, Hunan, China

${ }^{4}$ Health Management Center, the Second Xiangya Hospital of Central South

University, 139 Middle Renmin Road, Changsha 410011, Hunan, China

Full list of author information is available at the end of the article
}

C C The Author(s). 2021 Open Access This article is licensed under a Creative Commons Attribution 4.0 International License, which permits use, sharing, adaptation, distribution and reproduction in any medium or format, as long as you give appropriate credit to the original author(s) and the source, provide a link to the Creative Commons licence, and indicate if changes were made. The images or other third party material in this article are included in the article's Creative Commons licence, unless indicated otherwise in a credit line to the material. If material is not included in the article's Creative Commons licence and your intended use is not permitted by statutory regulation or exceeds the permitted use, you will need to obtain permission directly from the copyright holder. To view a copy of this licence, visit http://creativecommons.org/licenses/by/4.0/ The Creative Commons Public Domain Dedication waiver (http://creativecommons.org/publicdomain/zero/1.0/) applies to the data made available in this article, unless otherwise stated in a credit line to the data. 


\section{Introduction}

Primary hyperparathyroidism (PHPT) is a generalized endocrine disorder characterized by hypercalcemia and high or inappropriately normal concentrations of parathyroid hormone (PTH) [1-3]. Patients with PHPT may experience an array of symptoms, including nephrolithiasis, bone pain/fractures, gastrointestinal symptoms, thirst, and polyuria [4]. Parathyroid hormone activates the parathyroid hormone receptor, increasing bone and distal tubular calcium resorption [4]. Parathyroid hormone also plays a role in vitamin $\mathrm{D}$ metabolism; it activates vitamin D 1-alpha hydroxylase, which increases the renal synthesis of 1,25-dihydroxyvitamin $\mathrm{D}$ to enhance dietary calcium absorption [4]. Levels of PTH may be regulated by serum magnesium [5-8]. Hypermagnesemia may cause hypocalcemia, through activation of calcium-sensing receptors in the parathyroid glands, thereby suppressing PTH secretion [5-8]. Magnesium deficiency may lead to the production of defective cyclic adenosine monophosphate in the parathyroid glands and in PTH target organs. This may be the principal mechanism underlying both impaired PTH secretion and endorgan resistance to $\mathrm{PTH}$, which together contribute to the development of hypocalcemia [9-11].

Magnesium is the second most common intracellular cation [12]. Its abundance facilitates its multiple functions in common, essential intracellular processes. It is a co-factor in multiple enzymatic reactions, including those related to energy metabolism and DNA and protein synthesis, and it participates in the regulation of ion channels [13]. Magnesium is essential for the regulation of muscular contraction, blood pressure, insulin metabolism, cardiac excitability, vasomotor tone, nerve transmission, and neuromuscular conduction [14]. Although PTH stimulates an increase in tubular magnesium reabsorption in patients with PHPT, the direct effect of hypercalcemia on tubular magnesium reabsorption is the opposite. As a result, the serum magnesium levels in patients with PHPT are usually normal or only slightly reduced [15]. However, the occurrence of hypomagnesemia in PHPT has been noted previously [16-18], and patients with more severe PHPT, manifested by high serum calcium, tend to have low serum magnesium [18]. These findings suggest that hypomagnesemia has a potential in predicting the severity of hypercalcemia in patients with PHPT.

To the end, the occurrence of hypomagnesemia in patients with PHPT has been noted previously; however, the association of hypomagnesemia and severity of primary hyperparathyroidism remains unknown. In the present study, using a retrospective review of 307 consecutive PHPT patients who were continuously hospitalized, we investigated the association of hypomagnesemia with biochemical and clinical manifestations in patients with PHPT.

\section{Materials and methods}

\section{Study design and patients}

We performed a retrospective review of 307 hospitalized patients with PHPT who were continuously admitted to the Second Xiangya Hospital of Central South University, which is a tertiary hospital in Changsha, Hunan Province, Central South of China, from January 2010 to August 2020. The data collection was performed by trained endocrinologists. Patients diagnosed with secondary hyperparathyroidism, tertiary hyperparathyroidism, familial hypocalciuric hypercalcemia $(\mathrm{FHH})$ were excluded from the study. Hypomagnesemia was defined as a serum magnesium level $<0.75 \mathrm{mmol} / \mathrm{L}$ [19]. Osteoporosis was defined, according to the World Health Organization criteria, as a bone mineral density (BMD) $\mathrm{T}$ score of -2.5 standard deviations (SD) below that of a healthy young individual of the same sex; BMD is most commonly measured using dual energy X-ray absorptiometry [20]. Anemia was defined as hemoglobin $<130 \mathrm{~g} / \mathrm{L}$ in males and $<120 \mathrm{~g} / \mathrm{L}$ in females [21]. Hypercalcemic crisis was defined as a serum calcium level $>3.5 \mathrm{mmol} / \mathrm{L}$ [22].

This study protocol was approved by the Ethics Committee of the Second Xiangya Hospital of Central South University. All study methods were carried out in accordance with relevant guidelines and regulations. All the patients provided informed consent for participating in this study.

\section{Medical history collection and anthropometric information}

Medical records were reviewed for age, sex, and symptoms of PHPT, including nephrolithiasis, fatigue, polydipsia, gastrointestinal symptoms, bone pain, and a history of osteoporosis and fractures. Patient height was measured to the nearest $0.1 \mathrm{~cm}$, and weight was recorded to the nearest $0.1 \mathrm{~kg}$, with the participant wearing light clothing. Body mass index (BMI) was calculated as weight in $\mathrm{kg}$ divided by height in $\mathrm{m}^{2}$.

\section{Biochemical measurements}

Serum levels of calcium, phosphorus, magnesium, $\mathrm{PTH}$, 25-hydroxyvitamin D (25[OH]D), albumin, and creatinine were recorded. Blood samples were collected from patients fasted overnight. Hemoglobin $(\mathrm{Hb})$ levels were measured using an automated hematology analyzer ADVIA 2120 (Siemens Healthcare Diagnostics, Germany). Serum albumin, calcium, phosphorus, and magnesium, and albumin were determined using an automatic biochemical analyzer (Abbott Laboratories, North Chicago, IL, USA). Albumin-corrected serum calcium was calculated using the following formula: corrected calcium $(\mathrm{mmol} / \mathrm{L})=$ serum calcium $(\mathrm{mmol} / \mathrm{L})+0.02 \times(40-$ serum albumin [g/L]) [23]. Serum creatinine levels were measured were measured by an enzymatic assay (Sarcosine 
oxidase method, Kanto Chemical, Tokyo, Japan) with a Roche Modular P800 automatic analyzer (Roche Diagnostics, Mannheim, Germany), and the estimated glomerular filtration rate (eGFR) was estimated using the CKD-EPI 2009 equations [24]. Serum PTH was measured using the automated chemiluminescence immunoassay (Siemens Healthcare Diagnostics, Erlangen, Germany). Serum $25(\mathrm{OH})$ D was measured using an enzyme-linked immunosorbent assay (Immunodiagnostic Systems Limited, Boldon, UK). Urinary calcium and magnesium were measured by a colorimetric assay (Cobas System Roche, Pleasanton, CA, USA). All inter- and intra-assay coefficients of variation were less than $10 \%$ [25].

\section{Bone mineral density measurement}

Lumbar spine, femoral neck, and total hip BMD was measured using dual-energy X-ray absorptiometry with the GE Lunar Prodigy Advance $(\mathrm{CV} \leq 1 \%$; $\mathrm{T}$ score and $\mathrm{Z}$ score) in patients.

\section{Statistical analysis}

Data that were normally distributed were expressed as mean $\pm S D$, whereas data that did not follow a normal distribution were expressed as median (range). Values between groups were compared using Student $t$-test and Wilcoxon rank sum test for normally and non-normally distributed data, respectively. Spearman correlation coefficients were used to assess the association between serum magnesium and other variables. Linear regression was used to find relations between serum magnesium and other variables. Unadjusted and adjusted odds ratios were analyzed with logistic regression models. Statistical significance was set at $P<0.05$ (two-sided). All statistical analyses were performed using the SPSS software application (version 22.0: SPSS, Chicago, IL, USA).

\section{Results}

Among the 307 patients with PHPT in the present study population, 102 were males and 205 were females. The mean age of the study population was $52.2 \pm 14.6$ years. Seventy-seven patients (33 [32.4\%] males and 44 [21.5\%] females) had hypomagnesemia, accounting for $25.1 \%$ of the total population (Table 1). There was no difference in the duration of disease and serum phosphorus and $25(\mathrm{OH}) \mathrm{D}$ levels between the two groups. The average hemoglobin in the hypomagnesemia group was significantly lower than that in the normal magnesium group in both males and females; patients with hypomagnesemia also had a higher prevalence of anemia (53.8\% versus 27.3\%, $P<0.001$; Fig. 1 ). The hemoglobin levels were positively correlated with serum magnesium levels $(P<0.05$; Fig. 2$)$. The average serum calcium in the

Table 1 Demographic characteristics and serum parameters of study cohort

\begin{tabular}{|c|c|c|c|c|c|c|}
\hline & \multicolumn{3}{|l|}{ Males } & \multicolumn{3}{|l|}{ Females } \\
\hline & $\begin{array}{l}\text { normal magnesium } \\
\text { group }(n=69)\end{array}$ & $\begin{array}{l}\text { hypomagnesemia } \\
\text { group }(n=33)\end{array}$ & $\mathbf{P}$ & $\begin{array}{l}\text { normal magnesium } \\
\text { group }(n=161)\end{array}$ & $\begin{array}{l}\text { hypomagnesemia } \\
\text { group }(n=44)\end{array}$ & $\mathbf{P}$ \\
\hline Age (years) & $49.2 \pm 16.3$ & $45.6 \pm 15.8$ & 0.304 & $54.9 \pm 13.8$ & $52.3 \pm 12.0$ & 0.262 \\
\hline BMI $\left(\mathrm{kg} / \mathrm{m}^{2}\right)$ & $23.0 \pm 2.8$ & $20.8 \pm 2.9$ & 0.001 & $22.5 \pm 3.5$ & $22.3 \pm 4.0$ & 0.772 \\
\hline Hemoglobin $(\mathrm{g} / \mathrm{L})$ & $134 \pm 22$ & $115 \pm 23$ & $<0.001$ & $118 \pm 18$ & $107 \pm 17$ & $<0.001$ \\
\hline $\mathrm{eGFR}\left(\mathrm{mL} / \mathrm{min} / 1.73 \mathrm{~m}^{2}\right)$ & $76.2 \pm 37.7$ & $65.1 \pm 38.5$ & 0.238 & $80.3 \pm 41.0$ & $69.2 \pm 34.0$ & 0.141 \\
\hline Creatinine (umol/L) & $99.2 \pm 60.8$ & $138.0 \pm 112.7$ & 0.032 & $78.6 \pm 75.7$ & $91.0 \pm 51.7$ & 0.315 \\
\hline Albumin (g/L) & $38.6 \pm 3.3$ & $37.5 \pm 6.5$ & 0.301 & $39.3 \pm 9.4$ & $36.0 \pm 6.2$ & 0.026 \\
\hline Serum calcium (mmol/L) & $2.81 \pm 0.34$ & $3.08 \pm 0.46$ & 0.005 & $2.73 \pm 0.37$ & $3.10 \pm 0.59$ & $<0.001$ \\
\hline Corrected calcium (mmol/L) & $3.06 \pm 0.45$ & $3.40 \pm 0.59$ & 0.004 & $2.96 \pm 0.47$ & $3.50 \pm 0.66$ & $<0.001$ \\
\hline Serum phosphorus (mmol/L) & $0.71 \pm 0.20$ & $0.74 \pm 0.32$ & 0.823 & $0.80 \pm 0.28$ & $0.80 \pm 0.31$ & 0.944 \\
\hline Serum magnesium (mmol/L) & $0.94 \pm 0.12$ & $0.62 \pm 0.12$ & $<0.001$ & $0.93 \pm 0.12$ & $0.62 \pm 0.12$ & $<0.001$ \\
\hline 24-h urinary calcium (mmol/day) & $7.21 \pm 4.26$ & $9.55 \pm 8.75$ & 0.250 & $5.79 \pm 3.19$ & $7.51 \pm 5.52$ & 0.027 \\
\hline 24-h urinary phosphorus (mmol/day) & $15.7 \pm 5.9$ & $14.3 \pm 7.0$ & 0.394 & $13.0 \pm 6.5$ & $10.0 \pm 4.6$ & 0.018 \\
\hline 24-h urinary magnesium (mmol/day) & $2.91 \pm 0.94$ & $4.19 \pm 3.67$ & 0.046 & $2.54 \pm 1.75$ & $2.87 \pm 3.16$ & 0.444 \\
\hline PTH $(\mathrm{pg} / \mathrm{mL})$ & $46.2 \pm 50.1$ & $157.2 \pm 116.9$ & $<0.001$ & $50.2 \pm 63.5$ & $99.6 \pm 90.3$ & $<0.001$ \\
\hline 25(OH) D (ng/mL) & $34.4 \pm 18.2$ & $36.6 \pm 16.8$ & 0.659 & $32.4 \pm 16.5$ & $34.6 \pm 19.2$ & 0.516 \\
\hline Lumbar BMD $\left(\mathrm{g} / \mathrm{cm}^{2}\right)$ & $0.82 \pm 0.16$ & $0.77 \pm 0.15$ & 0.172 & $0.72 \pm 0.15$ & $0.69 \pm 0.13$ & 0.304 \\
\hline Hip BMD $\left(\mathrm{g} / \mathrm{cm}^{2}\right)$ & $0.73 \pm 0.16$ & $0.64 \pm 0.17$ & 0.054 & $0.65 \pm 0.17$ & $0.62 \pm 0.15$ & 0.430 \\
\hline $\mathrm{FN} \mathrm{BMD}\left(\mathrm{g} / \mathrm{cm}^{2}\right)$ & $0.60 \pm 0.14$ & $0.52 \pm 0.14$ & 0.024 & $0.53 \pm 0.14$ & $0.51 \pm 0.12$ & 0.428 \\
\hline
\end{tabular}

BMI body mass index, eGFR estimate glomerular filtration rate, $P T H$ parathyroid hormone, 25 (OH) $D, 25$-hydroxyvitamin $D, B M D$ bone mineral density, $F N$ femoral neck 


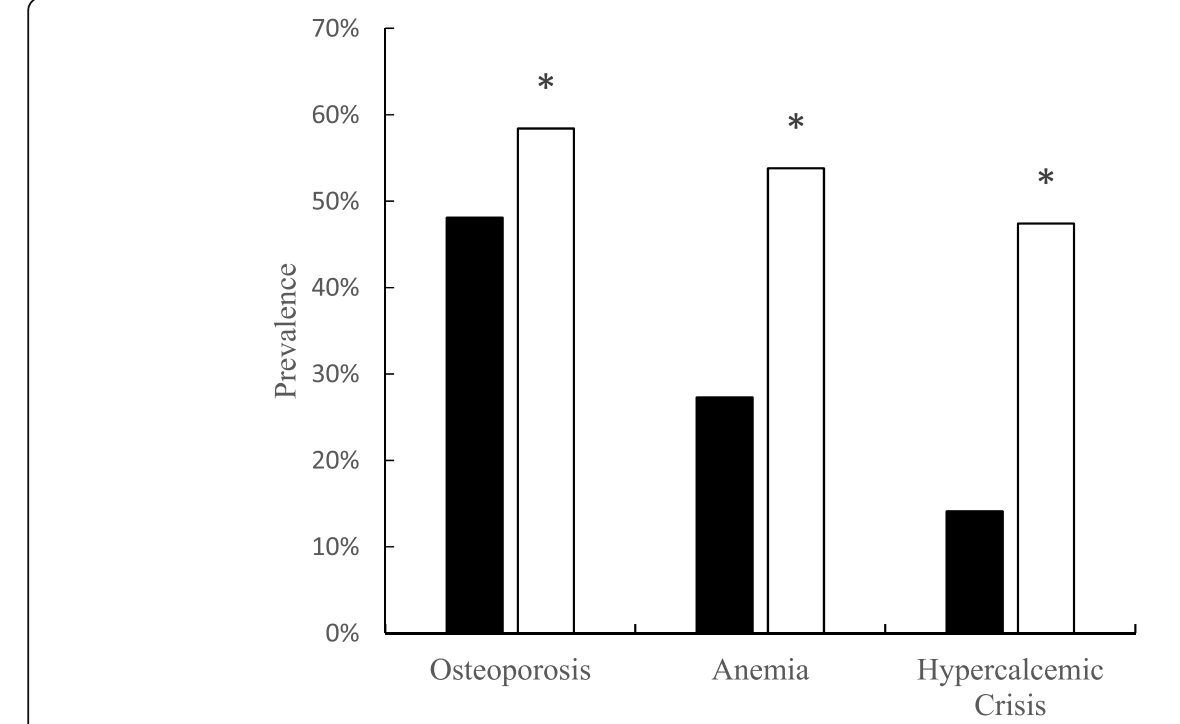

Normal magnesium

口Hypomagnesemia

Fig. 1 Prevalence of complications of PHPT patients. *vs normal magnesium group, $P<0.05$

hypomagnesemia group was significantly higher than that in the normal magnesium group in both males and females; patients with hypomagnesemia also had a higher incidence of hypercalcemic crisis $(47.4 \%$ versus 14.1\%, $P<0.001$; Fig. 1). Similarly, both serum PTH and calcium levels were negatively correlated with serum magnesium $(P<0.05$; Fig. 2$)$. In females, low serum albumin levels were associated with hypomagnesemia. Similarly, there was a decreasing trend in serum albumin levels in males with hypomagnesemia, but it did not reach statistical significance. The femoral neck BMD was significantly lower in the hypomagnesemia group in males (Table 1). Moreover, a weak but significant positive correlation was observed between total hip and femoral neck BMD and serum magnesium $(P<0.05$; Fig. 2$)$. The hypomagnesemia group had, on average, a lower lumbar and hip $\mathrm{T}$ score (Table 2) and a higher prevalence of osteoporosis than the normal magnesium group (58.4\% versus $41.7 \%, P<0.05$; Fig. 1 ).

The typical symptoms of PHPT, such as nephrolithiasis, bone pain/fractures, polyuria or polydipsia, were more common in the hypomagnesemia group (Table 3). There was a trend toward more gastrointestinal involvement in the hypomagnesemia group, but it did not reach statistical significance. The incidence of fatigue did not differ between the two groups.

Overall, the odds ratio (OR) for hypercalcemic crisis in patients with PHPT with hypomagnesemia versus normal magnesium was 5.50 (95\% confidence intervals [CI] 3.07-9.87, $P<0.001$; Table 4). The higher risk of hypercalcemic crisis in the hypomagnesemia group persisted after adjusting for age, sex, BMI, eGFR, and PTH (OR 3.43, 95\% CI 1.60-7.33, $P=0.001)$. The OR for anemia in the hypomagnesemia group was $3.30(P<0.001)$ and
$3.79(P=0.001)$ in unadjusted and multivariate adjusted analyses. Hypercalcemic patients also showed a 2.67 -fold higher risk for osteoporosis after multivariate adjustment $(P=0.006)$.

\section{Discussion}

The prevalence of hypomagnesemia was $25.1 \%$ in the total study population, $32.4 \%$ in males, and $21.5 \%$ in females. The occurrence of hypomagnesemia in PHPT has been noted previously and was confirmed in this study; a significant negative correlation was found between serum calcium and magnesium in patients with PHPT. These results are consistent with those of a previous study that included 73 hospitalized patients with PHPT [18]. Our results indicate that the higher prevalence of hypercalcemic crisis persisted after adjusting for eGFR and PTH levels in patients with hypomagnesemia. Magnesium levels are maintained within a normal range by a dynamic interplay among intestinal absorption, exchange with bone, and renal excretion, and disruption of these processes may cause hypomagnesemia [26, 27]. Magnesium is chiefly eliminated through renal excretion; thus, increased renal excretion leads to hypomagnesemia [28]. Although PTH stimulates an increase in tubular magnesium reabsorption in patients with PHPT, hypercalcemia has the opposite effect [15]. Hypercalcemia can cause hypomagnesemia owing to increased filtered calcium load in the loop of Henle, resulting in decreased reabsorption of magnesium [29]. In the present study, the mean $24 \mathrm{~h}$ urinary magnesium levels in the hypomagnesemia group were higher than those in the normal magnesium group in both males and females, but the difference was not statistically significant. This finding may be explained by the fact that we did not measure 


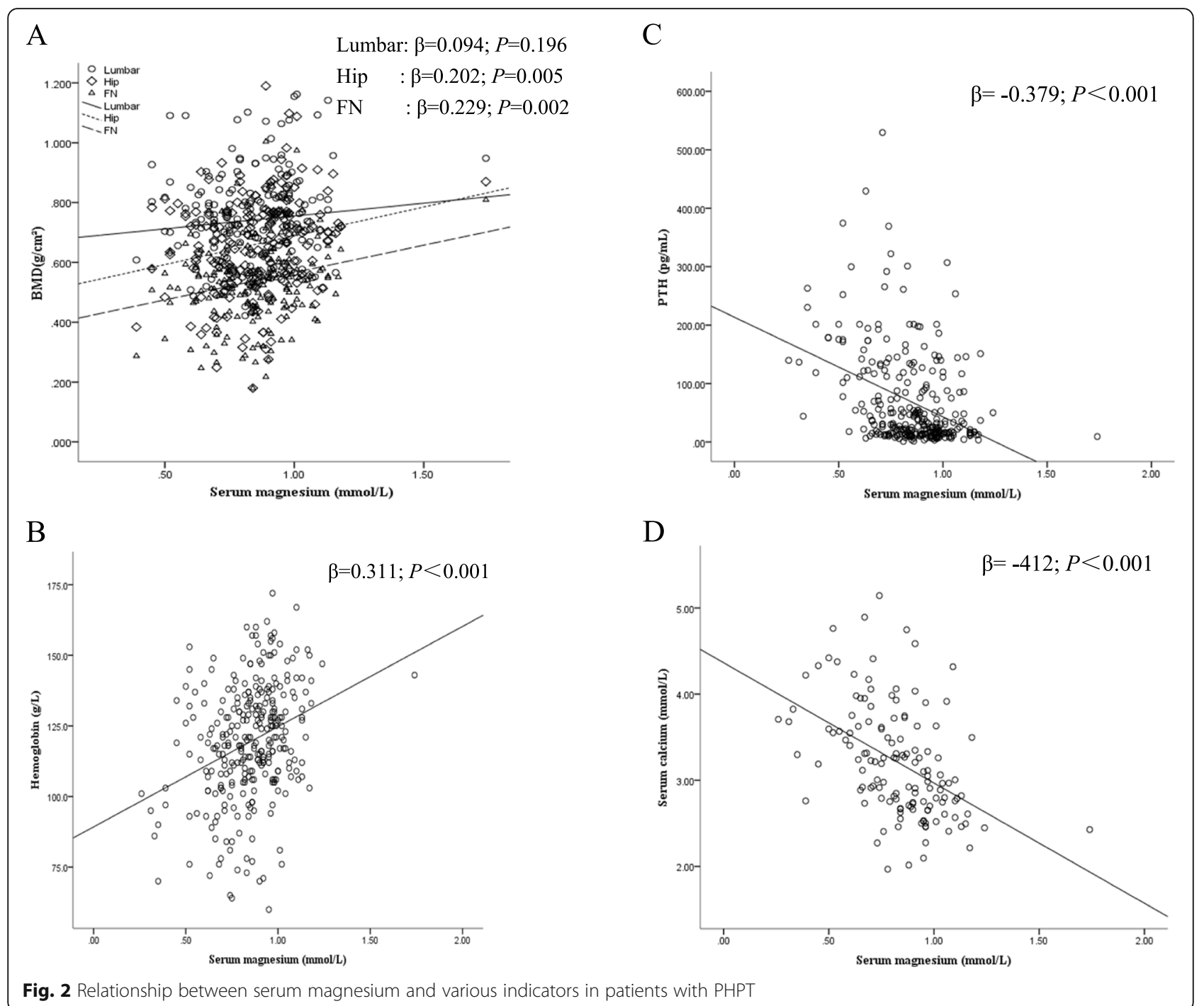

urinary creatinine and were unable to calculate the renal fractional excretion of magnesium. The renal fractional excretion of magnesium is more effective in evaluating renal magnesium excretion [30].

Hypomagnesemia can also be secondary to impaired intestinal magnesium absorption. A trend of a higher risk of gastrointestinal involvement in the hypomagnesemia group was observed in this study. Moreover, proton pump inhibitors, commonly used in gastrointestinal disorders, have been associated with hypomagnesemia in patients [31, 32]. Our study is limited in this aspect because data on the use of proton pump inhibitors were not obtained.

Our results suggest that the typical symptoms of PHPT were more common in the hypomagnesemia group. Patients with hypomagnesemia had a higher

Table 2 BMD of patients with PHPT

\begin{tabular}{llll}
\hline & normal magnesium group $(\boldsymbol{n}=\mathbf{1 3 6})$ & hypomagnesemia group $(\boldsymbol{n}=\mathbf{5 2})$ & $\mathbf{P}$ \\
\hline Lumbar T score & $-2.17 \pm 1.38$ & $-2.64 \pm 1.21$ & 0.032 \\
Lumbar Z score & $-0.89 \pm 1.46$ & $-1.87 \pm 1.40$ & $<0.001$ \\
FN T score & $-2.67 \pm 1.26$ & $-3.07 \pm 1.22$ & 0.053 \\
FN Z score & $-1.16 \pm 1.59$ & $-2.22 \pm 1.54$ & $<0.001$ \\
Hip T score & $-2.04 \pm 1.40$ & $-2.49 \pm 1.36$ & 0.045 \\
Hip Z score & $-0.97 \pm 1.47$ & $-1.85 \pm 1.63$ & $<0.001$ \\
\hline
\end{tabular}


Table 3 Clinical presentation of patients with PHPT

\begin{tabular}{llll}
\hline & normal magnesium group $(\boldsymbol{n}=\mathbf{2 2 0})$ & hypomagnesemia group $(\boldsymbol{n}=\mathbf{7 8})$ & $\mathbf{P}$ \\
\hline Symptomatic $\mathrm{n}(\%)$ & $157(71.4)$ & $71(91.0)$ & $<0.001$ \\
Nephrolithiasis $\mathrm{n}(\%)$ & $104(47.3)$ & $51(65.4)$ & 0.006 \\
Bone pain/fractures $\mathrm{n}(\%)$ & $54(24.5)$ & $31(39.7)$ & 0.011 \\
Polyuria/polydipsia n(\%) & $28(12.7)$ & $19(24.4)$ & 0.015 \\
Gastrointestinal involvement $\mathrm{n}(\%)$ & $17(7.7)$ & $11(14.1)$ & 0.097 \\
Asymptomatic $\mathrm{n}(\%)$ & $63(28.6)$ & $7(9.0)$ & $<0.001$ \\
\hline
\end{tabular}

prevalence of nephrolithiasis than patients with normal magnesium, which is consistent with the findings of other studies in the general population [33, 34]. This may be because magnesium-one of the inhibitors of stone formation-competes with calcium to bind to oxalic acid to form magnesium oxalate, a complex that is more easily soluble in urine [35]; at low magnesium levels, this competition is diminished. Hypercalciuria is a well-established risk factor for nephrolithiasis in patients with and without PHPT [36]. The mean $24 \mathrm{~h}$ urinary calcium levels in the hypomagnesemia group were higher than those in the normal magnesium group in both males and females, but the difference was not statistically significant.

The incidence of bone pain/fractures and osteoporosis was higher in the hypomagnesemia group than in the normal magnesium group. Even after adjusting for potential confounders such as age, sex, BMI, eGFR, and $\mathrm{PTH}$, the association remained essentially unchanged. This result is consistent with the known effect of hypomagnesemia on the prevalence of osteoporosis in the general population [37-39]. This is likely because low magnesium can alter trabecular bones owing to the formation of large but fragile crystals [40]. Moreover, low magnesium can reduce the vascular supply of bones [41] and increase inflammatory cytokines [42], which promote bone pain and fractures. High PTH activates osteoclasts more readily by enhancing RANKL expression, which increases calcium resorption and bone loss, promoting an osteoporotic state [43]. High calcium can cause renal tubular damage-which decreases the renal tubular concentration function-and increases urinary calcium excretion, which leads to polydipsia and polyuria [44]. This phenomenon may explain the finding that polyuria was more common in the hypomagnesemia group in our study.
The hypomagnesemia group showed significantly lower average hemoglobin levels than the normal magnesium group in both males and females, and the greater prevalence of anemia in the hypomagnesemia group persisted after controlling for the presence of eGFR and PTH. These results suggest that the effect of hypomagnesemia on anemia in PHPT is independent of the biochemical severity of the disease. The higher prevalence of anemia with hypomagnesemia has been described in individuals without PHPT [32, 45-47].

The present study has certain limitations. First, data on other risk factors for hypomagnesemia were not obtained for our patient population, such as the use of proton pump inhibitors. Second, urinary creatinine and ionized and intracellular free calcium and magnesium levels were not assessed, and effects of magnesium supplementation was not studied. Third, BMD data were available only for approximately three-fifth of the cohort, and distal forearm BMD was not assessed. Fourth, these finding are related to a hospitalized PHPT populations. Thus, these relationships cannot be immediately translated to PHPT outpatients. Lastly, considering the retrospective nature of this study, causal inferences between hypomagnesemia and different clinical features and complications of PHPT cannot be assumed.

Despite these limitations, this study had several strengths. First, this study evaluated data from a large cohort of PHPT patients. Second, blood measurements were performed at the same hospital laboratory. Third, we assessed the prevalence of hypomagnesemia in patients with PHPT. Fourth, this is the first study that assessed whether there is any association between serum magnesium and severity of primary hyperparathyroidism. Finally, we found that hypomagnesemia, which is a frequent electrolyte disorder in PHPT patients, is associated with severity of primary hyperparathyroidism. It is

Table 4 Complications of patients with PHPT

\begin{tabular}{|c|c|c|c|c|c|c|}
\hline & \multicolumn{3}{|c|}{ Unadjusted } & \multicolumn{3}{|c|}{ Adjusted for age, gender, BMI, eGFR and PTH } \\
\hline & OR & $95 \% \mathrm{Cl}$ & $\mathbf{P}$ & $\overline{\mathrm{OR}}$ & $95 \% \mathrm{Cl}$ & $P$ \\
\hline Osteoporosis & 1.76 & $1.05-2.97$ & 0.034 & 2.67 & $1.33-5.37$ & 0.006 \\
\hline Anemia & 3.30 & $1.86-5.87$ & $<0.001$ & 3.79 & $1.76-8.14$ & 0.001 \\
\hline Hypercalcemic Crisis & 5.50 & $3.07-9.87$ & $<0.001$ & 3.43 & $1.60-7.33$ & 0.001 \\
\hline
\end{tabular}


not known whether correcting hypomagnesemia with magnesium supplements in PHPT patients will reduce the progression of PHPT and other associated comorbidities. Further prospective studies with a higher number of patients are needed for this purpose.

In conclusion, we found that hypomagnesemia was associated with higher serum calcium and PTH, and clinical symptoms were more common in patients with hypomagnesemia. In addition, PHPT patients with hypomagnesemia had a higher prevalence of osteoporosis, anemia, and hypercalcemic crisis.

\section{Acknowledgements}

Not applicable.

\section{Informed consent}

Informed consent was obtained from all individual participants included in the study.

\section{Financial disclosure}

They declare that they have no financial disclosures.

\section{Authors' contributions}

Ding $\mathrm{Na}$ and Guo Tao are directly responsible for patients evaluations, data collection, manuscript draft; Liu Shu-Ying, Wang Qin-Yi, Qu Xiao-Li, Li YongFang helped in collecting patients' data; Ou Yang-Na is responsible for statistical analysis; Sheng Zhi-Feng and Yang Yan-Yi is responsible for the original idea. All authors approved the final manuscript and taking final responsibility for the paper.

\section{Funding}

This work was supported by grants from the National Nature Science Foundation of China [grant numbers 81870622], the Hunan Nature Science Foundation [grant number 2018JJ2574], the Changsha Nature Science Foundation [grant number kq2014251] and Bethune Charitable Foundation, BCF [grant number G-X-2019-1107-3].

\section{Availability of data and materials}

The datasets used and/or analysed during the current study are available from the corresponding author on reasonable request.

\section{Declarations}

\section{Ethics approval and consent to participate}

This study protocol was approved by the Ethics Committee of the Second Xiangya Hospital of Central South University. All research procedures in this study were in accordance with the ethical standards of institutions.

\section{Competing interests}

They declare that they have no conflict of interest.

\footnotetext{
Author details

${ }^{1}$ National Clinical Research Center for Metabolic Diseases, Hunan Provincial Key Laboratory of Metabolic Bone Diseases, Department of Metabolism and Endocrinology and Health Management Center, The Second Xiangya Hospital of Central South University, Changsha, Hunan, China. ${ }^{2}$ Department of Surgery, the First Affiliated Hospital of Hunan Normal University, Changsha 410005, Hunan, China. ${ }^{3}$ Hospital Infection Control Center, the Second Xiangya Hospital of Central South University, 139 Middle Renmin Road, Changsha 410011, Hunan, China. ${ }^{4}$ Health Management Center, the Second Xiangya Hospital of Central South University, 139 Middle Renmin Road, Changsha 410011, Hunan, China.
}

Received: 27 April 2021 Accepted: 7 August 2021

Published online: 20 August 2021

\section{References}

1. Walker MD, Silverberg SJ. Primary hyperparathyroidism. Nat Rev Endocrinol. 2018;14(2):115-25. https://doi.org/10.1038/nrendo.2017.104.

2. Khan AA, Hanley DA, Rizzoli R, Bollerslev J, Young JE, Rejnmark L, et al. Primary hyperparathyroidism: review and recommendations on evaluation, diagnosis, and management. A Canadian and international consensus. Osteoporos Int. 2017;28(1):1-19. https://doi.org/10.1007/s001 98-016-3716-2.

3. Borsari S, Pardi E, Pellegata NS, Lee M, Cetani FJ. Loss of p27 expression is associated with MEN1 gene mutations in sporadic parathyroid adenomas. Endocrine. 2016;55(2):1-12.

4. Silva BC, Cusano NE, Bilezikian JP. Primary hyperparathyroidism. Best Pract Res Clin Endocrinol Metab. 2018;32(5):593-607. https://doi.org/10.1016/j. beem.2018.09.004

5. Navarro JF, Mora C, Macia M, Garcia JJ. Serum magnesium concentration is an independent predictor of parathyroid hormone levels in peritoneal dialysis patients. Perit Dial Int. 1999;19(5):455-61. https://doi.org/10.1177/ 089686089901900509.

6. Navarro JF, Mora C, Jiménez A, Torres A, Foundation JG. Relationship between serum magnesium and parathyroid hormone levels in hemodialysis patients. Am J Kidney Dis. 1999;34(1):43-8. https://doi.org/10.1 016/S0272-6386(99)70106-X.

7. Ohya M, Negi S, Sakaguchi T, Koiwa F, Ando R, Komatsu Y, et al. Significance of serum magnesium as an independent correlative factor on the parathyroid hormone level in uremic patients. J Clin Endocrinol Metab. 2014;99(10):3873-88. https://doi.org/10.1210/jc.2013-4396.

8. Steen O, Khan A. Role of Magnesium in Parathyroid Physiology. In: Role of magnesium in parathyroid physiology: springer Milan; 2015.

9. Ursula Q. Michaela, Hoffmann, Marc, Freichel, et al. paradoxical block of Parathormone secretion is mediated by increased activity of Ga subunits. J Biol Chem. 2000;276(9):6763-9.

10. Johannesson AJ, Raisz LG. Effects of low medium magnesium concentration on bone resorption in response to parathyroid hormone and 1,25dihydroxyvitamin D in organ culture. Endocrinology. 1983;113(6):2294-8. https://doi.org/10.1210/endo-113-6-2294.

11. Allgrove J, Adami S, Fraher L, Reuben A, Riordan JL. Hypomagnesemia: study of parathyroid hormone secretion and function. Clin Endocrinol. 1984 21(4):435-49. https://doi.org/10.1111/j.1365-2265.1984.tb03230.x.

12. Elin RJ. Magnesium: the fifth but forgotten electrolyte. Am J Clin Pathol. 1994;102(5):616-22. https://doi.org/10.1093/ajcp/102.5.616.

13. Flatman PW. Magnesium transport across cell membranes. J Membr Biol. 1984;80(1):1-14. https://doi.org/10.1007/BF01868686.

14. Uwe GB, Joachim S, Klaus KJ. Magnesium in prevention and therapy. Nutrients. 2015;7(9):8199-226.

15. King RG, Stanbury SW. Magnesium Metabolism in Primary Hyperparathyroidism. Clin Sci.1970(2);39:281.

16. Barnes BA, Krane SM, Cope O. Magnesium studies in relation to hyperparathyroidism. J Clin Endocrinol Metab. 1957;17(12):1407-21. https:// doi.org/10.1210/jcem-17-12-1407.

17. Hanna S, North KAK, Macintyre I, Fraser RJ. Magnesium metabolism in parathyroid disease. Br Med J. 1961;2(5262):1253-6. https://doi.org/10.1136/ bmj.2.5262.1253.

18. Sutton RA. Plasma magnesium concentration in primary hyperparathyroidism. Br Med J. 1970;1(5695):529-33. https://doi.org/10.1136/bmj.1.5695.529.

19. Rooney MR, Lutsey PL, Alonso A, Selvin E, Chen LY. Serum magnesium and burden of atrial and ventricular arrhythmias: the atherosclerosis risk in communities (ARIC) study. J Electrocardiol. 2020;62:20-5. https://doi.org/10.1 016/j.jelectrocard.2020.07.008.

20. KANIS JJ. Assessment of fracture risk and its application to screening for postmenopausal osteoporosis: synopsis of a WHO report. Osteoporos Int. 1994;4(6):368-81. https://doi.org/10.1007/BF01622200.

21. Anke $H$, Matthias $N$, Henry V, Heike W, Uwe P, Hofbauer LC, et al. Interactions of anemia, FGF-23 and bone in healthy adults - results from the study of health in Pomerania (SHIP). J Clin Endocrinol Metab. 2020; 106(1):e288-99. https://doi.org/10.1210/clinem/dgaa716.

22. Cannon J, Lew Jl, Surgery CC. Parathyroidectomy for hypercalcemic crisis: 40 years' experience and long-term outcomes. Surgery. 2010;148(4):807-13. https://doi.org/10.1016/j.surg.2010.07.041. 
23. Meng L, Liu S, Al-Dayyeni A, Sheng Z, Zhou Z, Wang XJ. Comparison of initial clinical presentations between primary hyperparathyroidism patients from New Brunswick and Changsha. Int J Endocrinol. 2018;18:1-6.

24. Armas JB, Research M. Incidence of vertebral fracture in europe: results from the European prospective osteoporosis study (EPOS). J Bone Miner Res. 2002;17(4):716-24.

25. Li S, Ou Y, Zhang H, Zhang Z, Zhou H, Liu L, et al. Vitamin D status and its relationship with body composition, bone mineral density and fracture risk in urban central south Chinese postmenopausal women. Ann Nutr Metab. 2014;64(1):13-9. https://doi.org/10.1159/000358340.

26. Alexander RT, Hoenderop JG, Bindels RJ. Molecular determinants of magnesium homeostasis: insights from human disease. J Am Soc Nephrol. 2008;19(8):1451-8. https://doi.org/10.1681/ASN.2008010098.

27. Seo JW, Park TJ. Magnesium metabolism. Electrolyte Blood Press. 2008;6(2): 86-95. https://doi.org/10.5049/EBP.2008.6.2.86.

28. Costello R, Wallace TC, Rosanoff A. Magnesium. Adv Nutr. 2016;7(1):199-201. https://doi.org/10.3945/an.115.008524

29. Crook MA, Hally V, Panteli JV. The importance of the refeeding syndrome. Nutrition. 2001;17(7-8):632-7. https://doi.org/10.1016/S0899-9007(01)00542-1.

30. Zhang X, Del Gobbo LC, Hruby A, Rosanoff A, He K, Dai Q, et al. The circulating concentration and 24-h urine excretion of magnesium dose- and time-dependently respond to Oral magnesium supplementation in a Metaanalysis of randomized controlled trials. J Nutr. 2016;146(3):595-602. https:// doi.org/10.3945/jn.115.223453.

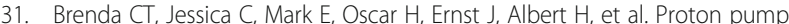
inhibitors and hypomagnesemia in the general population: a populationbased cohort study \%J American journal of kidney diseases. Am J Kidney Dis. 2015;66(5):775-82.

32. Biyik Z, Yavuz YC, Urology LA. Association between serum magnesium and anemia in patients with chronic kidney disease. Int Urol Nephrol. 2020; 52(10):1935-41. https://doi.org/10.1007/s11255-020-02525-8

33. Tavasoli S, Taheri M, Taheri F, Basiri A, Bagheri FJ. Evaluating the associations between urinary excretion of magnesium and that of other components in calcium stone-forming patients. Int Urol Nephrol. 2018;51(2):279-84. https:// doi.org/10.1007/s11255-018-2036-1.

34. Levy FL, Adams HB, Pak CY. Ambulatory evaluation of nephrolithiasis: an update of a 1980 protocol. Am J Med. 1995;98(1):50-9. https://doi.org/10.1 016/S0002-9343(99)80080-1.

35. Massey LJ. Magnesium therapy for nephrolithiasis. Magnes Res. 2005;18(2): 123-36.

36. Curhan GC, Taylor EN. 24-h uric acid excretion and the risk of kidney stones. Kidney Int. 2008;73(4):489-96. https://doi.org/10.1038/sj.ki.5002708.

37. Saito N, Tabata N, Saito S, Andou Y, Onaga Y, Iwamitsu A, et al. Bone mineral density, serum albumin and serum magnesium. J Am Coll Nutr. 2004;23(6):701S-3S. https://doi.org/10.1080/07315724.2004.10719412.

38. Orchard TS, Larson JC, Alghothani N, Bout-Tabaku S, Cauley JA, Chen Z, et al. Magnesium intake, bone mineral density, and fractures: results from the Women's Health Initiative observational study. Am J Clin Nutr. 2014 99(4):926-33. https://doi.org/10.3945/ajcn.113.067488.

39. Castiglioni S, Cazzaniga A, Albisetti W, Maier JJ. Magnesium and osteoporosis: current state of knowledge and future Research directions. Nutrients. 2013;5(8):3022-33. https://doi.org/10.3390/nu5083022.

40. Cohen L, Kitzes R. Infrared spectroscopy and magnesium content of bone mineral in osteoporotic women. Isr J Med Sci. 1981;17(12):1123-35.

41. Warburton DE, Nicol CW, Gatto SN, Bredin SS, Management R. Cardiovascular disease and osteoporosis: balancing risk management. Vasc Health Risk Manag. 2007:3(5):673-89.

42. Mazur A, Maier JA, Rock E, Gueux E, Nowacki W, Rayssiguier YJ, et al. Magnesium and the inflammatory response: potential physiopathological implications. Arch Biochem Biophys. 2007;458(1):48-56. https://doi.org/10.1 016/j.abb.2006.03.031.

43. Duque EJ, Elias RM, Toxins RM. Parathyroid hormone: a uremic toxin. Toxins (Basel). 2020;12(3):189-200. https://doi.org/10.3390/toxins12030189.

44. Natochin IV, Bogolepova AE. Possible mechanisms of polyuria in progressive chronic renal failure. Ter Arkh. 2000;72(6):15-20.

45. Zhan Y, Chen R, Zheng W, Guo C, Lu L, Ji X, et al. Association between serum magnesium and Anemia: China health and nutrition survey. Biol Trace Elem Res. 2014;159(1-3):39-45. https://doi.org/10.1 007/s12011-014-9967-X
46. Xu X, Hall J, Byles J, Shi ZM. Dietary pattern, serum magnesium, ferritin, Creactive protein and anaemia among older people. Clin Nutr. 2015;36(2): 444-51. https://doi.org/10.1016/j.clnu.2015.12.015.

47. Yu L, Song J, Lu X, Zu Y, Wang SX. Association between serum magnesium and erythropoietin responsiveness in hemodialysis patients: a cross-sectional study. Kidney Blood Press Res. 2019;44(3):354-61. https://doi.org/10.1159/ 000500921.

\section{Publisher's Note}

Springer Nature remains neutral with regard to jurisdictional claims in published maps and institutional affiliations.

\section{Ready to submit your research? Choose BMC and benefit from:}

- fast, convenient online submission

- thorough peer review by experienced researchers in your field

- rapid publication on acceptance

- support for research data, including large and complex data types

- gold Open Access which fosters wider collaboration and increased citations

- maximum visibility for your research: over $100 \mathrm{M}$ website views per year

At $\mathrm{BMC}$, research is always in progress.

Learn more biomedcentral.com/submissions 